simplicity and easy preparation being a great boon in a ship. During the patient's confinement to bed he was kept in a canvas swinging cot by an open port.

\section{Clinical atotes:}

\section{MEDICAL, SURGICAL, OBSTETRICAL, AND THERAPEUTICAL.}

\section{NOTE ON THE CAUSE AND CURE OF A FORM OF BACKACHE.}

By Str Jamps SAWyter, KNT, M.D. LoNd, F.R.C.P, SENIOR PHYSICIAN TO THE QUKEN'S HOSPITAI, AND PROFESSOR OF MEDICINE IN QUEEN'S COLLEGE, BrRMINGHAM.

EARLY in the year 1881, in a note which was published in a weekly professional journal, I asked the attention of my brethren to a form of backache which had not, so far as I know, been described before. ${ }^{1}$ I desire now to refer to this subject again, and to record that my further experience in practice has confirmed my previous remarks upon the point in question.

Subjective symptoms are always important diagnostic signs, and they are often clear therapeutic indications. Amongst such sensations backache is frequently a leading symptom, and also one which is pressingly dwelt upon by patients. Of backache there are divers forms. Dr. George Johnson, in an able clinical lecture, and Mr. William Squire, in a practical memorandum, have drawn the attention of the profession to many of these. ${ }^{2}$ But they have not mentioned a variety of backache in which the cause of the pain is traceable to the condition of the large bowel. I find that some patients complain of a pain, aching, dull, and heavy in character, and extending "right across the back." When asked to point out its position, they indicate this by carrying $a$ hand behind the trunk and drawing the extended thumb straight across the back, in a transverse line, about half-way between the inferior angles of the scapulæ and the renal region. This pain I venture to attribute to a loaded colon; I conclude I have correctly found its proximate cause in fæcal accumulation in the large intestine. I have found it disappear after the exhibition of an efficient cathartic. This form of backache is a concomitant of habitual constipation, and is especially significant of the alvine sluggishness of sedentary persons. In such a condition, as I have stated elsewhere, I find alces, given in combination with iron, to yield the best results. ${ }^{3}$ We owe the valuable suggestion of combining iron with aloes, when aloes is given for laxative purposes, to the late Sir Robert Christison. He showed that the cathartic property of aloes is much increased by its combination with sulphate of iron. Dr. Neligan, Dr. Kent Spender, and Dr. David Bell have confirmed this experience. I prefer socotrine aloes, and I give of it one, two, or three grains in a pill, combined with a quarter of a grain of sulphate of iron and one grain of extract of hyoscyamus. This pill should be taken every night. We must aim at producing a full alvine evacuation after breakfast. When a saline cathartic is indicated, I usually employ the oldfashioned Rochelle salt. This "goes" well with tea, coffee, or cocoa. One or two teaspoonfuls may be taken at breakfast, dissolved in a large cupful of one of these beverages.

Birmingham.

\section{CASE OF COCAINE POISONING."}

BY C. S. KILHAM, L.R.C.P., \&c.

ON Nov. 9th, 1886, at 12.10 noon, John B-accidentally took $4 \frac{4}{3}$ grs. of cocaine hydrochlorate in the form of solution. At 12.30 he was seized with severe cramps in the stomach, nausea, throbbing and feeling of bursting in his head, failure of eyesight, loss of use of his legs, incoherence of speech and confusion of ideas, and drowsiness, but could always answer questions if roused. No delirium; appeared

1 British Medical Journal, Feb. 19th, 1881. 2 Loc. cit., Feb. 12th, 1881

3 Contributions to Practical Medicine, p. 48. Cornish Brothers, 1886. - Read before the Sheffield Medico-Chirurgical Society, Nov, 25th, 1886. as if drunk, and got quite helpless. Brandy was given to him, and he vomited after it, but only the remains of food. About 12.50 he commenced sweating most profusely, shirt \&c. being soaked through, perspiration streaming down his face and body, and his head steaming. Pupils were normal and equal. No loss of taste. The sweating lasted some time, and was succeeded by very severe prostration, shivering, and feeling of impending death. At intervals the patient had severe cramps in the stomach, with retching and vomiting of a quantity of clear mucus, which relieved the pain. About 1.15 P.M. the pulse became intermittent (missing every fifth beat). This was accompanied by cyanosis of the face, and intense feeling of suffocation over the cardiac region. Relief was afforded by sinapisms. The pulse varied from 80 to 86 , never more, and became gradually regular. About 1.45 P.M. he began to have cramps in the legs and feet (especially on dorsal surface of right foot), and tingling and numbness in both hands. Later on the pupils became dilated. The vomiting and cramps ceased about 4 P.M. (unless food was taken), but the drowsiness, throbbing of head, and prostration continued up to 6 P.M., when the patient began to get warm and feel relieved. The improvement continued, and he could be moved at 8.30 P.M. There was great weakness, with swimming of head all night.

Next day there was still weakness, continual vomiting, a dry leathery feeling in the mouth, with loss of taste, partial loss of power in the legs, and tingling and numbness of the fingers, especially of the right hand. These symptoms commenced nearly thirty-six hours after taking the cocaine, and most of them disappeared in twenty-four hours. The loss of power in the legs lasted three days, and the tingling and numbness of fingers longer. He was not able to write a letter until the sixth day, as he could not feel the pen between his fingers before. An emetic was at first given, with sinapisms over the heart and stomach; afterwards warmth and stimulants (principally compound spirit of ammonia).

Remarks. - The solution of cocaine had been made at least twelve months, but appeared all right. The patient was in the habit of taking $\frac{1}{4}$ gr. of cocaine for neuralgia of the stomach. The dose taken was $4 \frac{4}{5}$ gr. of hydrochlorate of cocaine. The official dose is up to 1 gr. Martindale, in his book on "Coca and Cocaine, \&c." mentions two cases where larger doses were taken. In one case (of attempted suicide) 23 grs. of cocaine were taken without "seriously injurious effect." In the other case 32 grs. of cocaine were taken within three hours, but the symptoms varied considerably from those in the case under notice. The most remarkable symptoms were the severe sweating, the intense prostration, and the intermittent pulse. The last symptom I have not seen mentioned before.

Sheffield.

\section{A CASE OF RETRO-GESOPHAGEAL ABSCESS, CACSING} DEATH BY PRESSURE ON THE TRACHEA.

By Philip D. Turner, M.B. Lond., LATE HOUSE-SURGEON, VICTORIA HOSPITAL FOR CHILDREN.

I AM indebted to Dr. Julian Evans for permission to publish this case, which occurred at the Victoria Hospital in April last.

T. H. M- , an infant, aged three months, had been attending the hospital as an out-patient for some weeks for congenital syphilis. It first came towards the end of March with a strongly marked syphilitic eruption, which was followed in the beginning of April by the appearance of multiple subcutaneous phlegmons in the limbs. On April 19th there was an attack of dyspncea, which passed off in a few minutes. On the $22 \mathrm{nd}$, as the mother was bringing it to the hospital, the child was seized, according to her account, quite suddenly with dyspncea, and became of a very dusky colour. She hurried to the hospital, where it was at once admitted. There was, on admission, great dyspnœa, with considerable retraction of the thorax; colour very dusky; pulse rapid and feeble; voice not at all hoarse. Hot fomentations were applied to the neck, and the child placed in a steam tent. An hour after admission the respirations became more unfrequent and gasping, the colour very bad, and the pulse scarcely perceptible. Tracheotomy was therefore at once performed. After the operation the child rallied considerably. The recession almost, ceased and the colour improved. About three hours later, however,
the breathing got worse, the recession increasing aggin 